\title{
Rural Life in Late Socialism
}

\section{Politics of Development and Imaginaries of the Future}

\author{
Phill Wilcox | ORCID: 0000-0002-1617-6938 \\ Bielefeld University, Bielefeld, Germany \\ phill.wilcox@uni-bielefeld.de
}

Jonathan Rigg | ORCID: 0000-0002-6563-4640

University of Bristol, Bristol, UK

jonathan.rigg@bristol.ac.uk

\author{
Minh T.N. Nguyen \\ Bielefeld University, Bielefeld, Germany \\ minh.nguyen@uni-bielefeld.de
}

\begin{abstract}
Late socialist countries are transforming faster than ever. Across China, Laos and Vietnam, where market economies coexist with socialist political rhetoric and the Communist party state's rule, sweeping processes of change open up new vistas of imaginaries of the future alongside uncertainty and anxiety. These countries are three of very few living examples that combine capitalist economics with party state politics. Consequently, societal transformations in these contexts are subject to pressures and agendas not found elsewhere, and yet they are no less subject to global forces than elsewhere. As all three countries maintain substantial rural populations, and because those rural areas are themselves places of change, how rural people across these changing contexts undertake future making is a timely and significant question. The contributions in the issue address this question by engaging with lived experiences and government agendas across Laos, China and Vietnam, showing a politics of development in which desire and hope are entangled with the contradictions and struggles of late socialism.
\end{abstract}

\section{Keywords}

rural - late socialism - Asia - development - aspirations 
I know that I will have a different life from my parents. I came from our village in the [Lao] countryside to the city to study and now I have a good job. At university [in China] the teachers tell us that in the future we can be rich. I want to have my own business one day and make enough money to support my parents.

These are the words of a student from a rural area of northern Laos, studying at a Chinese university, to one of the authors in 2019. Now aged 21, this young person is entering adult life at a time of unprecedented change. The socialist rhetoric that marked the generation above him remains, but the economic policies of socialism, along with its vision of the future, are receding fast, to become a memory.

These words are echoed in social transformations throughout late socialist Asia. ${ }^{1}$ Across China, Laos and Vietnam, where market economies coexist with socialist rhetoric and the Communist party state's rule, sweeping processes of change open up new vistas of opportunity and imaginaries of the future alongside uncertainty and anxiety. These countries are three of the few living examples that combine capitalist economics with party state politics and attempt to manage both simultaneously. Consequently, societal transformations in these contexts are subject to pressures and agendas not found elsewhere, and yet they are no less in the thrall of global forces than in other parts of the world.

The speed of change across these late socialist countries is unprecedented. Within a few decades, centralised planning has given way to market economic policies. But, at the same time, this loosening of the economic climate has not gone hand in hand with significant liberalisation of the political landscape, as the Communist party retains its singular leadership. How this political economic trajectory shapes ideas of the good life and imaginaries of the future in these countries is the primary theme of the papers in this special issue. Late socialist countries are not immune to the pressures of globalisation, neoliberalism and restructuring found elsewhere, but these dynamics intersect with socialist rhetoric and institutions, and manifest in people's lived experiences in unique and often contradictory ways. The seemingly contradictory union of socialist ideology with market-based economics provides a unique place for future aspirations to take root and unfold, while also engendering a distinct politics of development.

1 We utilise the term 'late socialist' to distinguish between countries that retain a nominal commitment to socialism and those that have formally abandoned any connection with the term and its ideology. 
Jackson notes that 'it is one thing to be alive; it is quite another thing to feel alive and to think that life is worth living' (2017: ix). Yet what constitutes a life worth living is an open question, and one that can take a very specific form depending on context while being driven by a general expectation of rising living standards. Electricity and Wifi are now regarded as life's essentials for many rather than a luxury only accessible to the elite. Focusing on transforming rural areas, we demonstrate in this introduction to the special issue how the question of what constitutes a good life in contemporary Laos, China and Vietnam is by no means straightforward. What appears to mark a good life, for example the desire for a higher standard of living, may be common across contexts, but routes to achieving it vary enormously, as does the politics of achievement. In some cases, achieving a good life may simultaneously take the form of an outright rejection of traditional customs and beliefs and embracing change. In other cases, it can encompass the reinvention, rethinking and appropriation of traditions as the means for future building and achieving life goals.

Following Jackson, our point of departure is that the quest for wellbeing or a good life is always a field of struggle in which people hold varying expectations and hopes for the future, depending on their social and economic positions. The achievement of a good life may be calibrated and measured individually ('what is your level of education?'), but it is not achieved individually. People are socially situated, and this enables and can impede personal achievement. Importantly, achievement is validated and non-achievement justified through such societal values and acts. This struggle is also defined by what Jackson terms 'existential dissatisfaction' (2011: ix). In other words, the pursuit of a good life is an open-ended struggle that might remain perpetually unfulfilled. It is, however, in this very pursuit that people, communities and nations justify their actions and politics.

People may equate a good life with a happy one (Carson 1978), but as we shall see, the ongoing presence of hope for something more has no clear endpoint at which the goal of happiness has been achieved (Berlant 2011). The question of whose project a successful and meaningful life is, and whether that is an individual or collective one, and the role of the state in shaping those aspirations is a recurrent issue. So too are questions of how future building has transformed from being the remit of the elite to being open to a broad spectrum of people across society. What is clear is that future building is not exclusively a state project, and people consistently stake their claims and participation in its direction. Scholarship on future making, and especially future making as part of rural lives in late socialist Asia, remains limited, and we intend to address this gap in the contributions that follow. As all three countries maintain substantial rural populations, taking changing rural life as a primary focus is an 
obvious place to start. All too often, it is assumed that urban spaces represent the heartlands of change, but rural areas are also transforming rapidly. As Rigg (2014) argues, it no longer makes sense to view the countryside as something inherently fixed and bounded, separate from urban spaces. Nor does it make sense to view the countryside as a static and unchanging entity, a relict space. In rejecting these assumptions, we recognise that much as hopes for the future are changing, the very landscapes in which those changes are grounded are also changing. How rural lives are transforming across these countries inevitably underscores a series of contradictions and tensions between global and local forces. They implicate on the questions of individual and collective agency in negotiating change and how people shape and are shaped by transformations around them.

This special issue's eleven contributions from across Laos, Vietnam and China demonstrate how these tensions are lived out in the everyday lives of people and government policies. Following this introduction, Ian Baird describes the nature of changing agricultural practices in southern Laos in an attempt for farmers to achieve higher crop yields for less work. Seb Rumsby argues for the prevalence of Christian conversion among the Hmong of northern Vietnam as an alternative strategy for development in the face of perceived failure by the state. These papers demonstrate the ambivalent relationship between desire and modernity and the tensions that stalk these dreams. For Baird, it was the private concerns of people over the use of increased fertilisers and the long-term consequences of so doing. A quick return is one thing, but at risk of the land providing for the next generation. This demonstrates the precarity of livelihood making in the face of sometimes increasingly difficult living conditions. The alternative to this is migration, something that is a choice, sometimes a constrained choice, or not a choice at all, as Guido Sprenger outlines in his paper about relocated villages and the illusive power of the state. These papers demonstrate the future-oriented visions of the good life, and the worries regarding its achievement.

The importance of having a choice in what one desires, or at least appearing to, is a recurrent theme in all the papers. For Ruijing Wang, there is a choice to be made for those who wish to do away with their customs against their elders' wisdom and authority, and make the case that, in the contemporary world, it is possible for a baby born with a birth defect to be an accepted part of Akha society. For Tuan Anh Nguyen and his co-authors, being a single mother should be possible without being reprehensible, even where patriarchal structures continue to predominate. Acceptable life choices are a theme also picked up by Roy Huijsmans, in his demonstration that the Lao school system may instil possible career choices in rural Lao schoolchildren yet give them no way 
to achieve them. In growing economies that demand a vast supply of low-cost labour, it is therefore unsurprising that labour migration is a common strategy for rural households in late socialism, as outlined by Hy Van Luong. As rural people migrate to the cities, urban lifestyle in turn becomes a model for the countryside to emulate, as Lan Wei outlines in her account of the changing architecture of the house in a model village in southern China. For Zhi-Nong Li's Tibetan informants, it is a choice between polygamous, particularly polyandrous, marital unions, which suit their particular ideas and practices of care but are incompatible with being a modern member of society and state-approved forms of marriage. As such, desire in material and spiritual terms, for belonging and autonomy, for tradition and modernity, at the same time, is part of the struggle for a good life at work, at home and in private. Moreover, members of the same society will aspire in different ways because desire is itself dependent on one's life situation (Appadurai, 2004). Their desires do not map neatly on to what is possible: such possibilities are sometimes uncomfortably linked to what is acceptable, and what is acceptable can be contested by local people and the state. How these matters manifest themselves in the unique context of rural late socialism is the focus of this issue.

Finally, we argue for the logical grouping of late socialist Asian countries. Much as we began with the story of the young migrant from the Lao countryside who went to a city, then to China and aimed to establish his own business in Laos, this transcends the conventional groupings of (North)east Asian vs Southeast Asian studies and provides valuable insights across the conventional boundaries of area studies. The contributions that follow draw from a wide range of disciplines and provide richer data as a result, although most of them take ethnography as a central if not the sole research method. This approach allows for detailed consideration of the how, why and directions of rural transformations as the economy opens further. Changing rural areas are a crucial place to think with and through in this discussion.

Places of Change and Changing Places

\subsection{Rural Transformations}

In an increasingly interconnected world, the days of a neat division between the rural and the urban are, for the most part, gone. For many, so too are the days where everyone in a rural settlement expected to become a farmer and that cycle of life to continue indefinitely through each generation. By contrast, many people who would once have been considered farmers may not own land themselves and/or may labour for other people. In traditional rice-growing areas, 
rice may also have given way to other industries or crops, including the rise of cash crops for short-term gain (Hsing 2010; Lyttleton and Li 2017; Nguyen, Gillen and Rigg 2020). Agricultural workers no longer merely exist to provide long-term staple foodstuffs for the population. As much as urban people, those living in rural areas aspire to what they see as an ideal life trajectory and actively craft their own future-making projects. For many, this means a different trajectory of expectations and actions from those undertaken by their parents, as we saw in the opening of this introduction.

The very role of agriculture within the countryside and societies more generally is changing with greater market expansion and technological intervention. This brings farmers into encounters with different actors with agendas of their own, including urban people, entrepreneurs and even those involved in business activities across borders (McAlister 2015; Grillot and Zhang 2017). Urban dwellers' and entrepreneurs' goals often intersect uncannily well with state programmes for development. Since 2007, the Greater Mekong Subregion has pursued a campaign of 'community, competition and connectedness' (Lyttleton 2017: 216) and in its vision for how the region should develop and grow in economic terms even if, as Lyttleton observes, what it means for a large number of the poor remains to be seen. Under such ambitious programmes, the countryside would be hard pressed not to demonstrate sweeping and far-reaching changes. Among others, the growth of rural industries is testament to changing uses of the countryside and also how the countryside is understood and perceived across the region (Long, Ye and Wang 2010; Rigg 2014; Sakata 2013). Consider, for example the Lao government policy of Turning Land into Capital (Dwyer 2017), which has encouraged mass development of rural areas, sometimes in relation to mass infrastructure projects. In the Lao case, this was apparent in the collapse of the Xi Pian-Xe Namoy Hydropower Dam in a remote area of southern Laos in 2018, with disastrous consequences for local residents (Shoemaker 2018). But even without this catastrophe, the countryside being utilised to fulfil state and individual ambitions for future prosperity represents how rural areas have transformed and been perceived differently over time, as shown by Sprenger's analysis of resettlement in Laos (see also Evrard and Baird 2017). These changes are often carved literally into the landscape, not least in the imposition of urban planning on rural landscape as part of the new socialist countryside programme in China that Wei explores in this issue.

\subsection{Places of Movement}

Rural areas are also places from which people migrate, to which they return and where they stay. Like development of infrastructure, the movement and non-movement of people has profound effects. Even the relocation from one 
rural area to another is a form of movement that changes the countryside in different ways. The circumstances under which this happens have profound implications for how the countryside is understood and imagined. The questions of who is moving and who is not, to where and for what, are worth asking outside a linear paradigm of rural to urban movement.

Rural inhabitants may maintain a view of the cities as places of opportunity and somewhere to better their life chances through education or employment and earn the necessary remittances that improve their family's prospects. Yet they usually maintain networks with people of similar rural origins and dynamic emotional and economic relationships with their rural households as strategies for dealing with the precarious nature and emotional stresses of migration, as Luong shows in his analysis of translocal households in Vietnam (see also Nguyen 2014; Nguyen and Locke 2014; Tappe and Nguyen 2019; Rigg and Salamanca 2011). Rural households are actively involved in the process of migration by their members, for instance, through the provision and conveyance of supplies to relatives working outside agriculture in urban areas. These linkages fuel not only practical needs but also ambitions and aspirations. Relatives in villages may then follow existing networks to work in cities, pursuing lives different from those of previous generations. Yet while rural inhabitants are no different from anyone else in harbouring dreams for their future, they are subject to limits on the fulfilment of those dreams. These limits might be simple bad luck or individual life situation, but often they can be traced to rural migrants' structural disadvantage that leads to a lack of money, low education and poor health, because of their exclusion from urban services and the biased structures of opportunities in the labour market (Nguyen and Locke 2014). These mean that they are disproportionately affected in case of economic slowdown or environmental crisis. Such limits have not hampered the significance of mobility for rural imagining of the future. Meanwhile, not all migration is voluntary and the rejection of mobility at times plays an equally important role in people's sense of agency and self-determination regarding their future, as Sprenger suggests. Clearly, migration and non-migrationcoerced, voluntary or a movement that has elements of both-are both constituting rural change, raising questions about the future of agriculture and rural livelihoods, particularly small-scale agriculture (Fox et al. 2018; Rousseau and Sturgeon 2019; Thieme 2008; Wilson, Hu and Rahman 2018). Talk of migration thus must also deal with the trauma of forced movement and its ramifications across communities and beyond (Dao 2016; Habich 2016; High 2013). 
Humans desire. This might be an immediate desire for the material and to participate in consumption (Miller 1987) or for the more abstract: wellbeing, prestige, reputation and respectability (Berlant 2011). As Jackson (2011) notes, it is unusual to find people without desires for anything whatsoever. Hope, the desire to have or to become something more, is an arguably universal state. The papers in this issue demonstrate the connection between the immediate and the intangible, between desires and actions. We highlight the importance of thinking through future aspirations as something one has (a capability) as well as does. This is what Appadurai (2004) calls for in his insistence that aspirations do not exist in a vacuum; they are often highly situational and contextual. What looks attractive in one context will not always do so in another. It may also vary with time. This is why High urges us to think of desire as 'a locally charged concept and as a way of thinking about the cosmological and symbolic commitments behind particular arrangements of economics and politics' (2014: 14). Desire impacts people in different ways, while reproducing existing social inequality, as demonstrated by several contributions in this issue which address ethnic (Rumsby, Wang) or societal minorities (Nguyen et al.) and their attempts to realise the good life amid a hegemonic landscape that seeks either to maintain or to ignore their marginalisation.

Desire is related to how modernity is understood, and what it means to be a modern citizen, of a country and of the world at large (Salemink 2015). There is a growing literature on social aspiration and desire in late socialist contexts (High 2014; Hoang 2015; Rofel 2007; Salemink 2015; Zhang 2010). Noted as emerging across these countries is what Rofel terms a 'desiring subject' (2007), a form of moral personhood that vies for belonging in a cosmopolitan world of development and modernity and yet remains immersed in nationalist sentiments. In his account of how development is understood by the Hmong of rural northern Vietnam, Rumsby demonstrates how this desiring subject arises from the margin. As the Hmong rely on the economistic moral guidance of Pentecostalism for their 'development' effort, they are subscribing to the modernising claims of both the church and the state, at the same time as they critique the state's lack of involvement in improving their lives. Similarly, the Chinese villages ready to incur significant debt to rebuild their houses following the blueprint of the government for a New Socialist Countryside (Wei) might grudgingly do so, but many would find in such state programmes a space for realising their aspirations to be modern and exemplar citizens (see also High 2014; Nguyen 2018b). What being modern actually means is an open question while people seem happy to forego some aspects of culture if these are 
no longer regarded as 'useful'; individuals, groups and cultural norms are not fixed or immutable. The challenge is that it is hard to second guess what these aspects might be. For instance: does land hold symbolic and cultural value beyond its productive role in rural livelihoods? And: to what degree does the power of the 'homeland' keep rural migrants connected to their villages of origin?

\subsection{The Limits of Desire}

Even in the time where vistas of opportunity seem wider than ever, according to Jackson (2011), the capacity to aspire (Appadurai 2006) has its limits. Much as these countries have changed, people have also come to be confronted with new challenges in mastering their destiny, doing well for themselves and their family or at the very least appearing to do so. With the changing social contract in which responsibility for care and wellbeing now rests with the family, rural people, faced with higher living costs and rising expectations, have few other options than migrating to urban and industrial centres for wage work, often incurring high social costs for the rural family. Luong demonstrates this trajectory clearly in his discussion of migrant work and migrants' separation from their dependent family members. For Nguyen et al., the desire to build a family as a single mother is confronted with structures of opportunities and property regimes that privilege the married couple. This demonstrates how choice is often made within a limited range of options, even if these are far wider than those of previous generations. In Laos, children are allowed to make career choices that are considered acceptable aspirations (Huijsmans), while farmers have the option to use more advanced methods of agriculture and are encouraged to do so even as this endangers ideas of rice as a sacred part of Lao culture (Baird). Under the Chinese rural renewal programme, peasants are encouraged to build modern, urban-style houses (Wei), even as the project is stalked by debt and financial mismanagement. As certain groups insist on or adopt unconventional ways of family making, such as polyandrous marriage (Li), single motherhood (Nguyen et al.) or translocal family (Luong), the stateapproved heterosexual and co-residing nuclear family remains the ideal, along with its norms and moral restrictions. Here we see one of the tensions outlined earlier, that of the individual versus the collective in negotiating processes of change. But given that all changes involve other people and wider society, future building always has an impact on other people and frequently demands their cooperation or acquiescence.

Although individual agency is ever present in how people imagine their future, some are in a far better position to exercise agency than others. Everyone can desire but not all necessarily have their desires met. The presence of desire 
and the illusive struggle for success or respectability remains and extends beyond the individual and the local. This again speaks to a tension between local, national, global and international processes of change. What one wants may not be what the state wants as the latter balances competing interests of economic freedom with maintaining its ongoing need for legitimacy. Or what the state wants may contradict what is possible within the parameters of its own agency. In late socialism, one may have economic freedom but not the latitude to trespass on politics or ask too many direct questions about the ongoing relevance of socialist ideology. Such is how the cultural intimacy of late socialism operates (Herzfeld 2016). We also see the limits of the state in enforcing its rules (see Rumsby, Wang) or the inconsistency with which it does so. This makes thinking through agency and how people exercise agency a frustratingly difficult task. At the same time, the desire for a better life-to be 'modern'seems to have almost universal traction, notwithstanding significant differences in the texture of what this means and how it is achieved (or not).

\subsection{Contradictory Desires}

Desire often manifests itself in contradictory ways. Even as they aspire for improvements, many people in the region express concerns about the pace of change. Desire thus is a negotiated and emergent process (High 2008, 2013; Rofel 2007) as well as one that is often highly gendered and defined by generational difference (High 2014; Huijsmans 2019; Rofel 1999). A good life is as such not necessarily interchangeable with a happy one. As Baird shows, modern agricultural technologies might increase the rice yield and incomes of farmers and liberate them from the labour-intensive techniques of traditional farming, and yet the sticky rice no longer tastes as good while the quality of land declines over time. Yet a return to traditional farming is perhaps no longer possible, while the promotion of organic farming is often driven by the ethical consumption demands of better-off consumers rather than a real concern with restoring ecological balance for the sake of farming communities. Wei's thoughtful characterisation of the changing architecture of the rural house indicates the tension between the desire for privacy and consumption centred around the individual and the longing for a communal sense of family life that is distinctly gendered and shaped by power relations between the old and the young. Nguyen et al.'s account of single mothers in rural Vietnam shows that, while becoming a single mother allows a woman to fulfil her desire for family making as a form of self-determination, the mothers continue to refer to the hegemonic value of marriage in evaluating their lives.

People's articulation of their aspirations and desires is frequently connected to reflections about duties and sacrifices, missed opportunities and uncertain- 
ties, as the paper on rural-urban migration in Vietnam by Luong suggests. Migrant workers talk of being materially better off through migration for both themselves and their families, but the question of for how long these trajectories of migration can be maintained is unanswered. The price of migration for work is living far removed from one's immediate family and entrusting care to someone else, or of struggling to keep a family together on a perilously small income. The desire to move and not move with the imagined consequences of both options is also articulated as a complex area of engagement by Sprenger in a paper that reflects on the importance of maintaining autonomy, or at least being seen to do so, over one's life choices. In the same vein, Huijsmans' paper on Lao schools demonstrates how the promise of education was held up as a means of social mobility for Lao schoolchildren, even if for the local authorities being able to show that all the children passed primary education was far more important than whether the children were actually academically capable. The state may foster children's dreams for the future but simultaneously denies them the means to achieve them. We return to this question of agency, assumed agency and the appearance of agency in the sections below.

Rather than individualised projects, desire is also political (High 2014; Nguyen 2018a; Rofel 2007). As the political economic landscape has changed, so too have the possibilities for desiring. As neoliberal restructuring shifts responsibility from the state to individuals, families and communities, migrating to a capitalist country or obtaining a top-spec mobile phone are now statesanctioned dreams. It was not very long ago that the household registration systems in China and Vietnam kept people in place whatever their aspirations might have been-mobility was impossible for the large majority of the rural population. In Laos, limited infrastructure and poverty also effectively limited the scope for movement. Consumerist desires have also been democratised in the sense that they are open even to people living in poverty. In fact, consumption has implicitly turned into a citizen duty. Whether such levels of consumption are actually achievable for an individual subject is another question. Rural migrants to the cities encounter a wider cross-section of people than before, intersecting those with vastly different levels of financial, political and cultural capital. One may have images held up of what one could become, or how life could be if one worked sufficiently hard. These may be motivational but have also the potential for cruelty and negative consequences for the aspiration holders when and if they are not fulfilled. As Berlant (2011) recognises, the end point will be not the fulfilment of those dreams but failure to realise them. Desire is a startlingly potent force in prompting people to actions, which in turn shape the unfolding of rural changes, at times even the direction of the state development agenda. 


\subsection{Future Building and Its Parameters}

In Development as Freedom, Sen (1999) argues that freedom should be the goal of development, at both individual and collective levels. He outlines the importance of eliminating forces that restrict freedom(s), such as political systems of repression, and increasing access to economic opportunities and public services. This flies largely in the face of those cheering on neoliberal economics and arguing for growth at any cost while holding the state to account for the outcomes of development. The papers in this issue underscore the prominent role for the state in late socialism, yet one that has been significantly reconfigured compared to the previous era.

At the heart of socialism is a future-making project premised on modernisation and the harmonisation of individual and collective desires. This project contrasts with the expectations of a continuing upward trajectory in individual accumulation of wealth and consumption possibilities under capitalism, what Beckert (2016:61) terms 'fictional expectations'. As the states of late socialism carry out agendas that reference both the utopian dreams of socialism and the fictional expectations of capitalism, the parameters of future aspirations are a contested area. During the height of state socialism, future making was a straightforward matter, although symbolism from this period remains visible in how everyone has a role in progressing the cause of socialism within the nation (Creak and Barney 2018). With the opening up of all these countries and the gradual disassembly of economic systems such as collectives, possible career choices and life trajectories have widened. So too has the remit of the state. The state's role has morphed into a guiding force behind these multiple changes (High and Petit 2013) and, by so doing, avoided making itself redundant (Gainsborough 2010; Yamada 2018). With its contradictory goals, the state can be simultaneously a force that foments and encourages dreams for the future and sets limits on them. In contrast to the austere years of socialism, mass consumption is now what constitutes good citizenship (Huijsmans and Lan 2015)

This means that state power is not felt consistently or statically across any of our contexts (Rathie 2017; Schwenkel and Leshkowich 2012; Zhang and Ong 2008). Several contributions to this special issue demonstrate how the personal intersects with the political in respect of private life in ways that either contest or legitimise state power. Some of Wang's Akha villagers mobilise the state's power in a bid to create changes in local perceptions towards what the Akha deemed abnormal births, such as twins or webbed feet, which require killing the infants through purification rituals. Through appealing to state laws, 
which deemed their cosmological tradition around the practice backward and barbaric, change-makers prevented the death of babies that would have previously been deemed unnatural. But while some villagers wanted the state to play a more prominent role in this issue, others worried about cosmological imbalance resulting from the state intervention taking its toll on the community. Li Zhinong, in contrast, tells us of how people practising polygamy, particularly polyandry, in Tibet prefer to hide these alliances from the state, regarding their private lives as their own business in which the state's authority should not interfere. These two accounts suggest that people selectively turn to the state's modernising agendas for their own purposes while continuing to embrace enduring practices that do not fit in these agenda. In the same vein, Luong's paper cautions against a straight contrast of care policies of state socialism versus the contemporary period, arguing that the dynamics of care have always been complicated and contested. It is worth keeping in mind, he points out, that even the universal promise of socialist care towards families did not always translate to very much in material terms. Finally, Nguyen and his co-authors suggest how the state approval of heterosexual marriage as the ideal basis of family shapes the very struggles for livelihoods and social recognition of single mothers in rural Vietnam, whom it however has to allow a space for family making on account of the women's specific moral claims.

While state agendas and individual desires are often mutually constituted, the state does not hold a monopoly over moral and political guidance. A good example is how the Hmong in northern Vietnam participated in alternative development programmes to those offered by the Vietnamese state through their conversion to Christianity (Rumsby). Through recognising their achievements as an exemplar of local development, however, the state is presenting itself as the patron of such development and thereby attempting to reassert its control over the ethnic minorities in the face of alternative powers such as Evangelical churches. This indeed plays into a more general policy orientation in which the state recasts its role as the supervisor and enabler of development, leaving the actual responsibilities to a broad range of social actors, including transnational actors (Derks and Nguyen 202O). In a related discussion on communities that stay and move in the face of government resettlement programmes, Sprenger shows the elusive appearance of the state. Its power presents itself at times very explicitly, other times more tacitly, but is never entirely absent.

Thus, desire can be acted upon with tacit or explicit state support. For Nguyen and his co-authors' interlocutors, living alongside other single mothers appears to be a choice but in reality functions far more as a survival strategy as this is not a preferable life situation in the view of the state, albeit tolerable to 
certain extent. Here again, we see the state at work in arbitrating what is and is not possible, what can and cannot be the subject of aspiration. The question of who has the responsibility to care for whom is also a question that has never gone away, even as Laos, China and Vietnam enter a new era of possibility and aspiration. People continue to rely on their families and networks for survival and the tension of individual versus the community is felt acutely and lived out in everyday life. This is no less complicated in late socialist Asia than it is anywhere else, and being an entirely free agent is perhaps the greatest risk of all. As Jackson (2011) suggests, happiness and satisfaction rest more on the awareness of one's possible limits and accepting what one has rather than accepting the risk of losing all in the hope of obtaining or becoming something more. Our interlocutors might not necessarily be happy at all times, but that does not deny their notion that a good life can be possible, sometimes precisely thanks to acceptance, resignation or compromise. As such, the struggle for wellbeing and the good life is closely intertwined with the recognition of having made the best of available options or acceptance, when very few were or are actually available.

What is clear is that desires, aspirations and future building across Laos, Vietnam and China continue to be shaped by the need to navigate state power. In Laos, the will for the country to develop and exit Least Developed Country status has been a cornerstone of Lao government policy for several decades (United Nations Economic Analysis and Policy Division 2018). But this does not mean that all forms of development are acceptable to the state, and those who 'do' development in these countries must balance a large number of competing interests (High 2014; Salemink 2015). In their respective papers, Sprenger and Rumsby demonstrate how locals negotiate their own agency by negotiating with considerably stronger interests at local, national and international levels. This leads to a complex relationship of parties showing limited tolerance for each other and skirting around issues of who has the right to do what, where and at what time. Here too, the role of the state is negotiated as part of the process of future building. Similarly, all the other papers in this issue suggest the dynamic interaction between people's desires and aspirations and the state's agenda and the workings of its power.

Amid the growing uncertainty and precarity of late socialist Asia, the expectation of a future of wellbeing and fulfilment is pervasive, and rural people are no less driven by this expectation. In his work on the experiences 
of waiting by poor people, Auyero (2011) noted that the more powerful the entity or thing being waited for is understood to be, the more people are prepared to wait for it. The papers that follow reveal people not only waiting, but taking active steps, sometimes over long periods of time, in the hope of getting what they want. For the rural subjects encountered in this special issue, aspiration remains constant, and its force is potent. Desires for rising living standards, obtaining and achieving more in exchange for less hard work, greater material comfort, greater security and care for self and family, and simultaneously belonging to community, nation and global modernity are what drive people in the contexts we study. They point to a recognisable direction of change in respect of what constitutes a good life (Rigg 2014).

People in late socialist Asia are little different from those elsewhere in the world. What differs in this case is the way in which they navigate change amid the particular political context of late socialism. The backdrop of capitalist economics combined with socialist institutions and rhetoric results in multifaceted and at times contradictory desires for the future. While some of these changes signify an embrace of apparently modern values and a rejection of the anachronistic, for example in respect to traditional gender roles and marriage forms, there are exceptions, of which the ongoing prevalence of polyandrous marriage in Tibet highlighted by Li is the most obvious. Sometimes these changes are hidden behind the tension between the individual and the collective, the local and the global, or the old and the new. These intersections of power often demonstrate competing agendas that play out in the lives of our interlocutors.

We have demonstrated the diverse ways in which hope for the future is articulated as a project for both individual subjects and the state. They suggest how understandings of hope, development and the good life inform and are informed by imaginaries of the future that are particular to late socialism. They produce a politics of development that happens alongside, through and around the state as people navigate discourses of development in imagining their future at individual and collective levels. While late socialist Asia also shows signs of a recognisable direction of change, there are some unique features. In contrast to strict neoliberal economics and its laissez-faire approach to the market, the role of the state is not diminishing. If anything, it shows signs of increasing in its prominence as promoter and guardian of social change. Nowadays, people are no longer asked to sacrifice for the nation, and it is possible for them to expect improvements for themselves and their family, but this expectation must continue to align with the interests of the nation and the state. 
People in late socialist Asia now have, in many respects, more choices. However, these are not limitless and our subjects navigate their lives against a backdrop of opportunities and limits. While talk of individual dreams is abundant, these are subsumed into the logics of development and capital accumulation by greater forces. This is why migrant workers may move to cities to build lives for themselves, but face exploitation as low-paid workers for businesses interested in little more than exploiting their labour. Invariably, they encounter the explicit or implied force of the state, which acts as a patron of their desires and promoters of futures, as well as a limiter of their aspirations. What drives them is, according to Jackson (2011), the presence of hope, and a belief that one can, somehow, become something more than what one has been or is currently. Optimism itself is surprisingly durable in a world of uncertainty and precarity (Berlant 2011).

At the time of writing this introduction, the world has once again entered a period of unprecedented uncertainty as states and populations are forced to engage with the harsh realities of Covid-19. The pandemic's heavy tolls on economies and societies around the world give a poignant twist to the hopes and aspirations of late socialist Asia that we have been discussing. What the world will look like at the end of this period and whether this will lead to any significant reordering of structures, systems and priorities is an open question and will require further research and close observation.

\section{Acknowledgments}

The special issue emerges from a conference in September 2019 that was generously co-funded by Bielefeld University's Centre for Interdisciplinary Research (ZIF). The editors are also grateful for the friendly and professional assistance of ZIF's conferencing team. The co-writing of the Introduction by Phill Willcox and Minh T.N. Nguyen was made possible by European Research Council funding via the project WelfareStruggles (grant agreement No 803614).

\section{References}

Appadurai, A. 2004. 'The Capacity to Aspire: Culture and the Terms of Recognition'. In Culture and Public Action, edited by V. Rao and M. Walton, 59-84. Stanford, CA: Stanford University Press.

Auyero, J. 2011. 'Patients of the State: An Ethnographic Account of Poor People's Waiting'. Latin American Research Review 46(1): 5-29. 
Beckert, J. 2016. Imagined Futures: Fictional Expectations and Capitalist Dynamics. Cambridge, MA: Harvard University Press.

Berlant, L. 2011. Cruel Optimism. Durham, NC: Duke University Press.

Carson, T. 1978. 'Happiness and the Good Life'. Southwestern Journal of Philosophy 9(3): $73-88$.

Creak, S., and K. Barney. 2018. 'Conceptualising Party-State Governance and Rule in Laos'. Journal of Contemporary Asia 48(4):1-24.

Dao, N. 2016. 'Political Responses to Dam-induced Resettlement in Northern Uplands Vietnam'. Journal of Agrarian Change 16(2): 291-317.

Derks, A., and M.T.N. Nguyen. 2020. 'Beyond the State? The Moral Turn of Development in South East Asia'. South East Asia Research 28(1): 1-12.

Dwyer, M.B. 2017. 'The New "New Battlefield": Capitalizing Security in Laos' Agribusiness Landscape'. In Changing Lives in Laos: Society, Politics, and Culture in a PostSocialist State, edited by V. Bouté and V. Pholsena, 192-220. Singapore: NUS Press.

Evrard, O., and I.G. Baird. 2017. 'The Political Ecology of Upland/Lowland Relationships in Laos since 1975'. In Changing Lives in Laos: Society, Politics, and Culture in a PostSocialist State, edited by V. Bouté and V. Pholsena, 165-191. Singapore: NUs Press.

Fox, J., Tuyen Nghiem, Ham Kimkong, K. Burni and I.G. Baird. 2018. 'Large-scale Land Concessions, Migration, and Land Use: The Paradox of Industrial Estates in the Red River Delta of Vietnam and Rubber Plantations of Northeast Cambodia'. Land 7(2): 77 .

Gainsborough, M. 2010. Vietnam: Rethinking the State. London: Zed Books.

Grillot, C., and J. Zhang. 2017. 'Ambivalent Encounters: Business and the Sex Markets at the China-Vietnam Borderland'. In Chinese Encounters in Southeast Asia: How People, Money and Ideas from China are Changing a Region, edited by P. Nyíri and D. Tan, 97-118. Seattle: University of Washington Press.

Habich, S. 2016. Dams, Migration and Authoritarianism in China. New York: Routledge.

Herzfeld, M. 2016. Cultural Intimacy: Social Poetics and the Real Life of States, Societies and Institutions. New York: Routledge.

High, H. 2008. 'The Implications of Aspirations'. Critical Asian Studies 40(4): 531-550.

High, H. 2013. 'Experimental Consensus: Negotiating with the Irrigating State in the South of Laos'. Asian Studies Review 37(4): 491-508. DoI: 10.1080/10357823.2013.7941 88.

High, H. 2014. Fields of Desire: Poverty and Policy in Laos. Singapore: Nus Press.

High, H., and P. Petit. 2013. 'Introduction: The Study of the State in Laos'. Asian Studies Review 37(4): 417-432. DoI: 10.1080/10357823.2013.833579.

Hoang, K.K. 2015. Dealing in Desire: Asian Ascendancy, Western Decline, and the Hidden Currencies of Global Sex Work. Oakland, CA: University of California Press.

Hsing, Y.-T. 2010. The Great Urban Transformation:Politics of Land and Property in China. Oxford: Oxford University Press. 
Huijsmans, R. 2019. 'Becoming Mobile and Growing Up: A “Generationed" Perspective on Borderland Mobilities, Youth, and the Household'. Population, Space and Place 25(3): 1-10.

Huijsmans, R., and T.N.H.L. Lan. 2015. 'Enacting Nationalism through Youthful Mobilities? Youth, Mobile Phones and Digital Capitalism in a Lao-Vietnamese Borderland'. Nations and Nationalism 21(2): 209-229.

Jackson, M. 2011. Life within Limits: Well-being in a World of Want. Durham, NC: Duke University Press.

Jackson, M. 2017. How Lifeworlds Work: Emotionality, Sociality, and the Ambiguity of Being. Chicago: University of Chicago Press.

Long, N., J. Ye and Y. Wang, eds. 2010. Rural Transformations and Development_China in Context: The Everyday Lives of Policies and People. Cheltenham: Edward Elgar.

Lyttleton, C. 2017. 'Stimulating Circuits: Chinese Desires and Transnational Affective Economies in Southeast Asia'. In Chinese Encounters in Southeast Asia: How People, Money and Ideas from China are Changing a Region, edited by P. Nyíri and D. Tan, 214-234. Seattle: University of Washington Press.

Lyttleton, C., and Y. Li. 2017. 'Rubber's Affective Economies: Seeding a Social Landscape in Northwest Laos'. In Changing Lives in Laos: Society, Politics, and Culture in a PostSocialist State, edited by V. Bouté and V. Pholsena, 301-326. Singapore: NUS Press.

McAlister, K. 2015. 'Rubber, Rights and Resistance: The Evolution of Local Struggles against a Chinese Rubber Concession in Northern Laos'. Journal of Peasant Studies 42(3-4): 817-837.

Miller, D. 1987. Material Culture and Mass Consumption. Oxford: Blackwell.

Nguyen, M.T.N. 2014. 'Translocal Householding: Care and Migrant Livelihoods in a Waste-trading Community of Vietnam's Red River Delta'. Development and Change 45(6): 1385-1408.

Nguyen, M.T.N. 2018a. 'Vietnam's "Socialization” Policy and the Moral Subject in a Privatizing Economy'. Economy and Society 47(4): 627-647.

Nguyen, M.T.N. 2018b. Waste and Wealth: An Ethnography of Labor, Value, and Morality in a Vietnamese Recycling Economy. New York: Oxford University Press.

Nguyen, M.T.N., and C. Locke. 2014. 'Rural-Urban Migration in China and Vietnam: Gendered Householding, Space Production and the State'. Journal of Peasant Studies $41(5): 855^{-876 .}$

Nguyen, T.A., J. Gillen and J. Rigg. 2020. 'Economic Transition without Agrarian Transformation: The Pivotal Place of Smallholder Rice Farming in Vietnam's Modernization'. Journal of Rural Studies 74: 86-95.

Rathie, M. 2017. 'The History and Evolution of the Lao People's Revolutionary Party'. In Changing Lives in Laos: Society, Politics and Culture in a Post-Socialist State, edited by V. Bouté and V. Pholsena, 19-55. Singapore: Nus Press.

Rigg, J. 2014. More than the Soil: Rural Change in Southeast Asia. Abingdon: Routledge. 
Rigg, J., and A. Salamanca. 2011. 'Connecting Lives, Living, and Location: Mobility and Spatial Signatures in Northeast Thailand, 1982-2009'. Critical Asian Studies 43(4): $55^{1-575}$.

Rofel, L. 1999. Other Modernities: Gender Yearnings in China after Socialism. Berkeley: University of California Press.

Rofel, L. 2007. Desiring China: Experiments in Neoliberalism, Sexuality and Public Culture. Durham, NC: Duke University Press.

Rousseau, J.-F., and J. Sturgeon. 2019. 'The Disappearance of Water Buffalo from Agrarian Landscapes in Western China'. Journal of Agrarian Change 19: 319-336.

Sakata, S. 2013. 'Rural Industries in Northern Vietnam: Strategies of Small-scaled Business Establishments in the Formation of Craft Villages'. In Vietnam's Economic Entities in Transition, edited by Shoko Sakata, 204-226. Basingstoke: Palgrave Macmillan.

Salemink, O. 2015. 'Revolutionary and Christian Ecumenes and Desire for Modernity in the Vietnamese Highlands'. Asia Pacific Journal of Anthropology 16(4): 388-409.

Schwenkel, C., and A.M. Leshkowich. 2012. 'Guest Introduction: How is Neoliberalism Good to Think Vietnam? How is Vietnam Good to Think Neoliberalism?' Positions $2 \mathrm{O}(2): 378-401$.

Sen, A. 1999. Development as Freedom. Oxford: Oxford University Press.

Shoemaker, B. 2018. The Lao Dam Collapse: A Tragedy Long in the Making. Available at www.newmandala.org/lao-dam-collapse-tragedy-long-making/.

Tappe, O., and M.T.N. Nguyen. 2019. 'Southeast Asian Trajectories of Labour Mobility: Precarity, Translocality, and Resilience'.TRaNS:Trans-Regional and-NationalStudies of Southeast Asia 7(Special Issue 1): 1-18.

Thieme, S. 2008. 'Sustaining Livelihoods in Multi-local Settings: Possible Theoretical Linkages between Transnational Migration and Livelihood Studies'. Mobilities 3(1): $51^{-71 .}$

United Nations Economic Analysis and Policy Division. 2018. Least Developed Country: Lao People's Democratic Republic Profile. Available at: www.un.org/development/ desa/dpad/least-developed-country-category-lao-peoples-democratic-republic .html (accessed: 28 April 2019).

Wilson, G., Z. Hu and S. Rahman. 2018. 'Community Resilience in Rural China:The Case of Hu Village, Sichuan Province'. Journal of Rural Studies 6o: 130-140.

Yamada, N. 2018. 'Legitimation of the Lao People's Revolutionary Party: Socialism, Chintanakan Mai (New Thinking) and Reform'. Journal of Contemporary Asia 48(5): 717738. Dor: 10.1080/00472336.2018.1439o81.

Zhang, L. 2010. In Search of Paradise: Middle-class Living in a Chinese Metropolis. Ithaca: Cornell University Press.

Zhang, L., and A. Ong. 2008. Privatizing China: Socialism from Afar. Ithaca, NY: Cornell University Press. 